\title{
Leakage of Microbial Endotoxin through the Implant-Abutment Interface in Oral Implants: An In Vitro Study
}

\author{
Rhoodie Garrana, ${ }^{1}$ Govindrau Mohangi, ${ }^{2}$ Paulo Malo, ${ }^{3}$ and Miguel Nobre ${ }^{4,5}$ \\ ${ }^{1}$ Department of Oral Medicine \& Periodontology, School of Oral Health Sciences, Faculty of Health Science, \\ University of the Witwatersrand, 7 York Road, Parktown 2193, Johannesburg, South Africa \\ ${ }^{2}$ Clinical Unit, Department of Oral Medicine \& Periodontology, School of Oral Health Sciences, Faculty of Health Science, \\ University of the Witwatersrand, Johannesburg, South Africa \\ ${ }^{3}$ Malo Clinic Health and Wellness, Av. dos Combatentes 43A, 1600-042 Lisbon, Portugal \\ ${ }^{4}$ Research and Development Department, Malo Clinics, Av. dos Combatentes 43A, 1600-042 Lisbon, Portugal \\ ${ }^{5}$ Oral Hygiene Department, Malo Clinics, Av. dos Combatentes 43A, 1600-042 Lisbon, Portugal \\ Correspondence should be addressed to Rhoodie Garrana; rmgarrana@gmail.com
}

Received 19 September 2016; Revised 24 November 2016; Accepted 12 December 2016

Academic Editor: Elizabeta Gjorgievska

Copyright (c) 2016 Rhoodie Garrana et al. This is an open access article distributed under the Creative Commons Attribution License, which permits unrestricted use, distribution, and reproduction in any medium, provided the original work is properly cited.

Background. Endotoxin initiates osteoclastic activity resulting in bone loss. Endotoxin leakage through implant abutment connections negatively influences peri-implant bone levels. Objectives. (i) To determine if endotoxin can traverse different implantabutment connection (IAC) designs; (ii) to quantify the amount of endotoxins traversing the IAC; (iii) to compare the in vitro comportments of different IACs. Materials and Methods. Twenty-seven IACs were inoculated with E. coli endotoxin. Six of the twenty-seven IACs were external connections from one system (Southern Implants) and the remaining twenty-one IACs were made up of seven internal IAC types from four different implant companies (Straumann, Ankylos, and Neodent, Southern Implants). Results. Of the 27 IACs tested, all 6 external IACs leaked measurable amounts of endotoxin. Of the remaining 21 internal IACs, 9 IACs did not show measurable leakage whilst the remaining 12 IACs leaked varying amounts. The mean log endotoxin level was significantly higher for the external compared to internal types $(p=0.015)$. Conclusion. Within the parameters of this study, we can conclude that endotoxin leakage is dependent on the design of the IAC. Straumann Synocta, Straumann Cross-fit, and Ankylos displayed the best performances of all IACs tested with undetectable leakage after 7 days. Each of these IACs incorporated a morselike component in their design. Speculation still exists over the impact of IAC endotoxin leakage on peri-implant tissues in vivo; hence, further investigations are required to further explore this.

\section{Introduction}

In conventional two-piece implant systems, the abutment is connected to the implant mechanically via a screw. This creates an interface through which leakage may occur. In 1977, the first dental implant was designed by Brånemark et al. and was manufactured for human implantation and consisted of a screw retained slip-fit butt-joint external hexagon connection [1]. The external hex connection was the first connection design and was used primarily as a carrier of the device into the mouth [1]. The external implant-abutment connection however does present with several mechanical and biological complications such as screw loosening, rotational misfit at the implant-abutment interface, and microbial penetration [2]. Implant-abutment connections have evolved greatly in an attempt to minimize these complications. Leakage however is not isolated to external connections and may occur in internal connection designs as well; however, the quantity of leakage is unknown in both design types. In 1986, one of the first internal implant-abutment connections was developed by Niznick [3]. This connection was designed with a $1.7 \mathrm{~mm}$ deep internal hexagon connection below a $0.5 \mathrm{~mm}$ wide 45 degree taper which proved to have superior force distribution properties when compared to the original external hexagon 
implant-abutment connection [2]. Since then, several variations of the internal and external implant-abutment connection were developed in an attempt to outperform previous designs. These include internal spline connections, Morsetaper connections, and Internal Octagon connections [3].

The implant-abutment interface acts as a reservoir for oral microorganisms $[4,5]$ that in turn may induce an inflammatory response within the peri-implant tissues with a resultant loss of peri-implant crestal bone $[6,7]$. As a result, studies [8] were conducted on the tightness of implant-abutment connections against corpuscular bodies (viable bacteria). In 2010, Harder et al. suggested that the mere ingress of bacterial endotoxins (requiring less of a micro gap) was enough to initiate the inflammatory cascade and tissue destruction that leads to peri-implant bone loss [9]; this concept was demonstrated by Hou et al. in 2013 [10] by the upregulation of osteoclasts by bacterial endotoxins. In Harder's study of two internal implant-abutment connections, he showed one to leak after only 5 minutes whilst the hermetic seal of the other remained intact after 168 hours. This study suggests vast variation in performance of implant-abutment connection seal even within design categories.

Research Motivation. Failure of the implant-abutment hermetic seal may lead to crestal bone loss and peri-implant disease, eventually leading to implant loss. A comparative performance analysis between current connections may highlight superior connection designs for future implant selection and planning.

Aim. The aim of this study was to investigate whether there is a difference in the ability of current implant connection designs to limit the movement of microbial endotoxins across the implant-abutment interface. If leakage does occur, we will, in addition, aim to quantify it and hence compare the various IACs implicated in this study.

\section{Materials and Methods}

This was an in vitro study conducted under controlled laboratory conditions to assess the seal of implant-abutment connections (IAC) at different time intervals over a seven-day period. The IACs tested are summarized below (see Figure 1 and Table 1).

All abutments were procured specifically for the respective implants according to manufacturer's specifications and were connected to the implant with a screw, torqued to supplier's stipulations. The sample size was convenient, based on the key research questions to be answered and on cost constraints. Analysis of variance (ANOVA) was used to analyse differences between the factors of time and implant connection.

2.1. Test Procedure. The limulus amoebocyte lysate test (LAL test) is a quantitative test for Gram-negative bacterial endotoxin. LAL is an aqueous extract of blood cells (amoebocytes) from the horseshoe crab (Limulus polyphemus). LAL reacts with bacterial endotoxin or lipopolysaccharide (LPS), which is a membrane component of Gram-negative bacteria. The

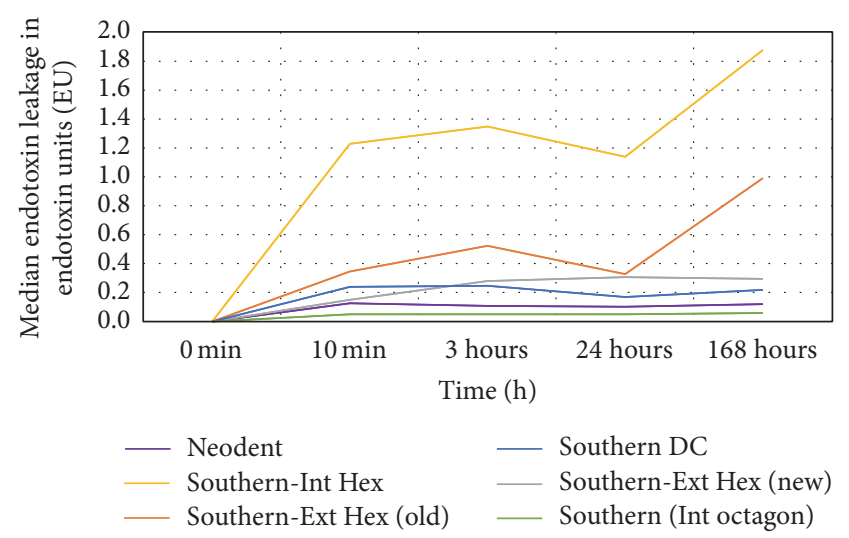

FIGURE 1: A line graph demonstrating median leakage versus time for each implant-abutment connection that leaked. Note. The above graph shows all implants that demonstrated measurable leakage. This excludes Ankylos and Straumann (Cross-fit connection and Synocta) which showed no measurable leakage.

test is based on the findings of Bang [11] who documented that endotoxin caused a fatal intravascular coagulation in the horse shoe crab species. This reaction is caused by the enzymatic conversion of a clottable protein which is derived from the circulating blood cell. This principle is used in a clinically modified test manufactured by Charles River known as Endosafe ${ }^{\circledR}$-PTS (pyrogen testing system) adhering to United States Pharmacopeia (USP) and is FDA approved (US license number: 1197). The LAL test detects the presence of microbial endotoxin. The standard endotoxin stock solution is prepared from a USP endotoxin reference standard that has been calibrated to the current WHO International Standard for endotoxin, that is, Endotoxin Standard [12]. One USP endotoxin unit (EU) is equivalent to one international unit (IU) of endotoxin [12].

Using the Endosafe-PTS requires the operator to follow 4 sequential steps:

(1) Instrument Operation. The machine is turned on by holding down the number 5 on the keypad; once the machine has turned on, the system will conduct a "system self-test" as it heats up to 37 degrees Celsius; this takes approximately 5 minutes.

(2) Insert the Cartridge. A pyrogen-free cartridge is removed from the pouch with the sample reservoirs facing upwards. The cartridge is placed firmly into the slot into the front of the Endosafe-PTS. Cartridges should be stored at temperatures between 2 and 25 degrees Celsius and allowed to reach room temperature prior to opening.

(3) Enter the Required Information. Once the cartridge has been placed into the unit, the unit registers the cartridge and prompts the user to enter identification information for data collection purposes after testing. This consists of a user ID, a cartridge lot number, and calibration number.

(4) Dispensing the Sample. Once all the information has been captured adequately, the Endosafe-PTS prompts 
TABLE 1: Type and number of implant abutment connections tested according to manufacturers specified torque value in newton centimeters $(\mathrm{Ncm})$.

\begin{tabular}{|c|c|c|c|c|c|c|}
\hline & Make & Design & Specifications & Connection & $\begin{array}{l}\text { Number of implants } \\
\text { to be tested }\end{array}$ & $\begin{array}{c}\text { Torque value to be } \\
\text { applied }(\mathrm{Ncm})\end{array}$ \\
\hline (1) & \multirow{5}{*}{ Southern Implants } & External Hex & $4 \mathrm{~mm} \varnothing 10 \mathrm{~mm} \mathrm{~L}$ & External & 3 & 20 \\
\hline (2) & & External Hex & $4 \mathrm{~mm} \varnothing 10 \mathrm{~mm} \mathrm{~L}$ & External & 3 & 45 (new) \\
\hline (3) & & Deep Conical (DC) & $4.0 \mathrm{~mm} \varnothing \times 11 \mathrm{~mm} \mathrm{~L}$ & Internal & 3 & 32 \\
\hline (4) & & Internal Octagon (IT) & $\begin{array}{l}4.1 \mathrm{~mm} \text { Body } \emptyset \\
\text { prosthetic platform } \\
4.8 \mathrm{~mm} \varnothing 10 \mathrm{~mm} \mathrm{~L}\end{array}$ & Internal & 3 & 32 \\
\hline$(5)$ & & Internal Hex & $4.2 \mathrm{~mm} \varnothing 10 \mathrm{~mm} \mathrm{~L}$ & Internal & 3 & 20 \\
\hline (6) & Neodent & Conical Connection & $4.3 \mathrm{~mm} \varnothing 10 \mathrm{~mm} \mathrm{~L}$ & Internal & 3 & 15 \\
\hline (7) & \multirow[b]{2}{*}{ Straumann } & $\begin{array}{l}\text { Bone Level Tapered } \\
\text { (BLT), Cross-fit-RC }\end{array}$ & $4.1 \mathrm{~mm} \varnothing, 10 \mathrm{~mm} \mathrm{~L}$ & Internal & 3 & 35 \\
\hline (8) & & Tissue Level, Synocta & $\begin{array}{l}4.1 \mathrm{~mm} \text { body } \varnothing, \\
4.8 \mathrm{~mm} \text { prosthetic } \\
\text { platform, } 10 \mathrm{~mm} \mathrm{~L}\end{array}$ & Internal & 3 & 35 \\
\hline (9) & Dentsply-Ankylos & Conical connection & $3.5 \mathrm{~mm} \emptyset 9.5 \mathrm{~mm} \mathrm{~L}$ & Internal & 3 & 15 \\
\hline
\end{tabular}

the user to dispense $25 \mu \mathrm{L}$ of the sample to be tested into each of the four reservoirs and press "enter." Pumps draw sample aliquots into the test channels thereby initiating the test. The test takes a maximum of 15 minutes depending on the amount of endotoxin present in the sample.

Bacterial endotoxin products derived from the E. coli species were used to inoculate the implant lumen. Four standard vials of 20-40 EU were reconstituted with $1 \mathrm{~mL}$ of pyrogenfree water. The reconstituted endotoxin was placed into the deepest part of the implant lumen.

The abutments were connected to the respective implants (see Table 1) according to the manufacturer's specifications using a calibrated torque controller of the respective manufacturer whilst the implant was secured firmly in the universal fixation clamp.

The implants were each submerged in pyrogen-free containers, containing pyrogen-free water and agitated by an oscillating plate. Samples $(25 \mu \mathrm{L})$ from each beaker were taken at $0 \mathrm{~min}, 10 \mathrm{~min}, 3$ hours, 24 hours, and 168 hours and dispensed into the reservoirs of a newly opened test cartridge. All IACs were vibrated in their suspension prior to taking the $168 \mathrm{~h}$ sample to dissociate any clumped endotoxin to provide a more accurate reading. Each test provided a reading in endotoxin units (EU) that ranged from $0.05 \mathrm{EU}$ to 10 EU. A negative control sample was taken from a container containing an implant not inoculated with endotoxin to ensure there was not any previous contamination of the pyrogen-free water or container. Each container was covered between readings to prevent ingress of atmospheric contaminants. The procedure was carried out under a laminar airflow cabinet. Sterile gloves and masks were worn at all times when handling the equipment. This information was recorded and tabulated. A new pipette tip was used for each sample taken. A calibrated pipette provided by Charles River was used to take equal samples of solution at every time interval preventing inaccuracies in sample volume which may distort readings. Testing took place at an approved laboratory at the University of the Witwatersrand under appropriate biosafety regulations which were approved by the Biosafety Board, approval number 20151201.

The IACs were tested for measurable leakage within a range of $0.05 \mathrm{EU}$ to $10 \mathrm{EU}$. This was the inherent range of the cartridge selected for testing. A randomized testing sequence was used to carry out testing in an unbiased order.

2.2. Data Analysis. The median endotoxin level for each implant at each time point, together with its $95 \%$ confidence interval, was calculated and presented graphically as a time profile plot (see Figure 1). The implant connection systems were compared (overall and selected comparisons) using a repeated measures Analysis of Variance (ANOVA) with factors time and implant connection and an AR covariance structure. A log-transformation of the endotoxin levels was used to meet the assumptions of the technique. Data analysis was carried out in SAS. The 5\% significance level was used [13].

2.3. Ethics and Biosafety Approval. An ethical waiver was granted by the Wits Research Ethics Committee. All implant firms or representatives agreed to the terms and conditions set by the Wits Research Legal Department prior to testing. Biosafety approval was granted unconditionally according to the terms and conditions stipulated by the Wits Biosafety board in terms of handling and discarding of hazardous substances. All relevant testing cartridges, implants, abutments, and accessories were sponsored by the firms or their representatives.

\section{Results}

3.1. Individual IAC Performance. Of the 9 connection types tested, 3 did not present with measurable leakage within the parameters of the study. These included Straumann Synocta, 
TABLE 2: Median and maximum endotoxin values for the maximum leak (at any time) for each implant abutment connection type that showed measurable leakage as well as the number of specific types that leaked.

\begin{tabular}{lccc}
\hline Implant & Number that leaked (out of 3) & Median & Maximum \\
\hline Neodent Drive CM & 2 & 0,351 & 0,575 \\
Southern Deep Conical (DC) & 3 & 0,312 & 0,494 \\
Southern-External Hex (new torque values) & 3 & 0,341 & 0,575 \\
Southern-External Hex (old torque values) & 3 & 0,992 & 4,180 \\
Southern-Internal Hexagon (M-series) & 3 & 5,290 & $>, 146$ \\
Southern-Internal Octagon (IT) & 1 & 0,146 \\
\hline
\end{tabular}

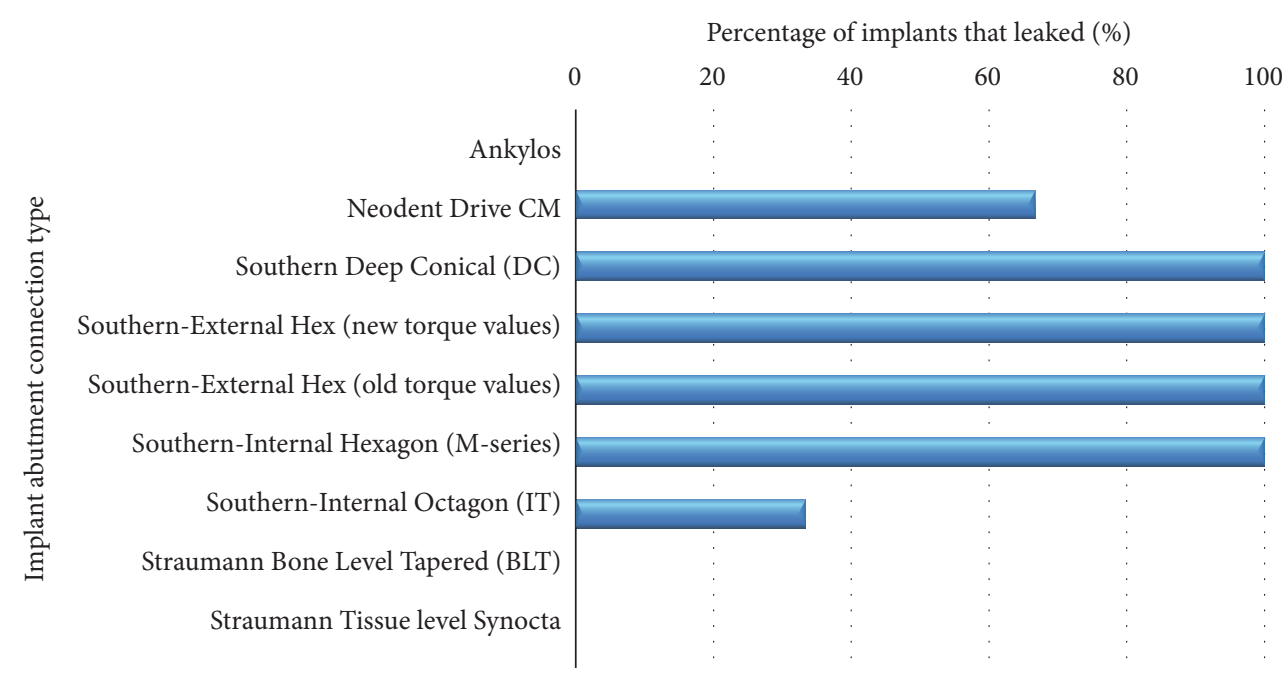

FIGURE 2: A bar graph showing the percentage (\%) of each implant-abutment connection type that leaked.

Straumann Cross-fit, and the Ankylos morse-like connection (see Figure 3). Of the remaining 6 connections, the leakages detected were as follows (see Table 2 and Figures 1, 2, and 3):

(i) The Neodent conical connection leaked a median amount of $0.351 \mathrm{EU}$ and a maximum of $0.575 \mathrm{EU}$ (see Table 2). Two of the three Neodent connections tested showed measurable leakage.

(ii) The Southern Deep Conical connection leaked a median amount of $0.312 \mathrm{EU}$ and a maximum of 0.494 EU. All three Southern Deep Conical connections tested showed measurable leakage.

(iii) The Southern-External Hex connection (tightened to the newly stipulated manufacturer specification of $45 \mathrm{Ncm}$ ) leaked a median amount of $0.341 \mathrm{EU}$ (see Figures 1 and 3) and a maximum of 0.575 EU. All 3 Southern-External Hex connections tested showed measurable leakage.

(iv) The Southern-External Hex connection (tightened to the former stipulated manufacturers specification of $20 \mathrm{Ncm}$ ) leaked a median amount of $0.992 \mathrm{EU}$ and a maximum of 4.180 EU. All 3 Southern-External Hex connections tested showed measurable leakage. (v) The Southern-Internal Hex connection leaked a median amount of 5.290 EU and a maximum unmeasurable leakage of over 10.000 EU. All 3 SouthernInternal Hex connections tested showed leakage.

(vi) The Southern-Internal Octagon connection leaked a median amount of $0.146 \mathrm{EU}$ (see Figures 1 and 3 ) and a maximum of 0.575 EU. Only one of the three Southern-Internal Octagon connections tested showed measurable leakage.

3.2. Comparison of Performances between External and Internal Design. The mean $\log ($ endotoxin) leakage was significantly higher for the external implant types compared to the internal implant types. This conclusion was made as the effects of implant type, time, and the implant type-time interaction were all significant $(p=0.015,<0.0001$, and 0.028, resp.) (see Figure 1).

\subsection{Comparison of Performances between "Like" Connection Types}

3.3.1. Southern-Internal Octagon (IT) versus Straumann Tissue Level Synocta. There was no significant difference in mean $\log$ (endotoxin) leakage between the two implant types. The effects of implant type, time, and the implant type-time 


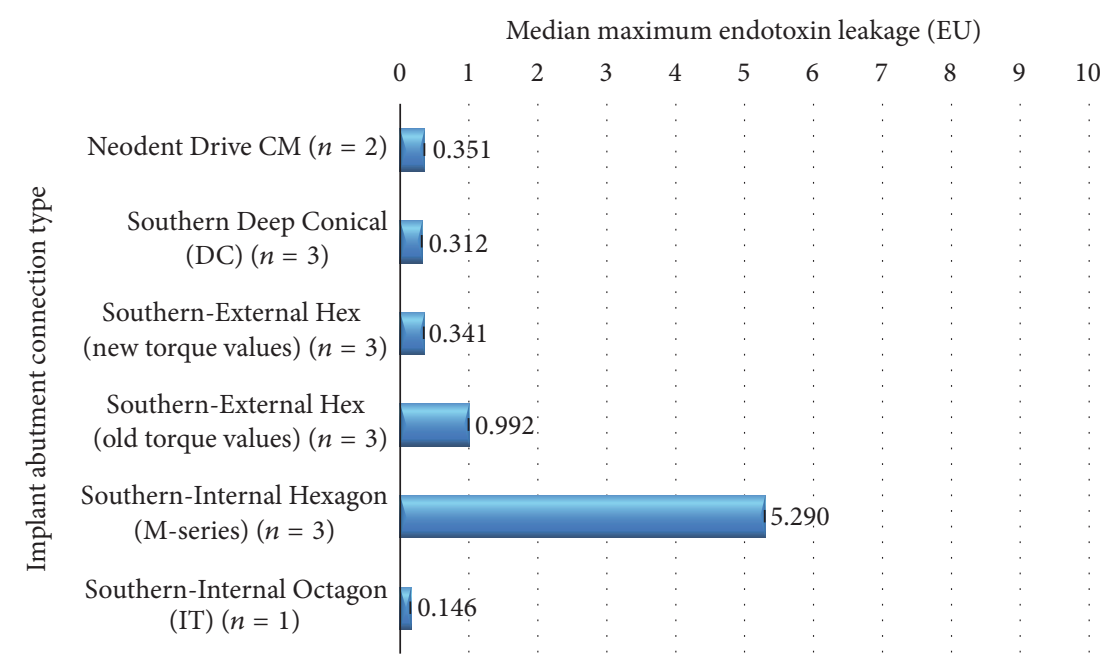

Figure 3: A graph demonstrating the median maximum leak values in endotoxin units (EU) for each implant-abutment connection type where $n=$ the number of IACs that leaked.

interaction were not significant $(p=0.60,0.072$, and 0.53 , resp.).

3.3.2. Neodent Drive CM versus Ankylos. There was no significant difference in mean $\log$ (endotoxin) leakage between the two implant types. This conclusion was achieved because the effects of implant type, time, and the implant type-time interaction were not significant $(p=0.13,0.10$, and 0.47 , resp.).

\subsubsection{Southern-External Hex: Old versus New Torque Values.} There was no significant difference in mean $\log$ (endotoxin) leakage levels between the two implant types torqued at different values.

This conclusion was achieved because the effects of implant type and the implant type-time interaction were not significant ( $p=0.073$ and 0.20 , resp.) whilst the effect of time was significant (with time they leaked more; see Figure 1) $(p=0.0001)$.

\section{Discussion}

The Straumann Synocta connection, Straumann Cross-fit, and Ankylos connections showed no measurable leakage within the parameters of this study over the 7-day testing period and hence performed most optimally out of the 9 tested IAC types within the parameters of this study. It is suspected that these IACs displayed no measurable leakage due to a combination of morse-like tapers and interlocking antirotational design mechanisms which create a high degree of intimacy between abutment and implant and prevent rotational movements, respectively.

The Southern-Internal Octagon showed measurable leakage in 1 of the 3 connections (see Table 2 and Figure 2). This leakage occurred at the $168 \mathrm{~h}$ reading and hence showed no statistically significant difference from the leakage obtained from the Straumann Synocta. The Neodent Drive CM IAC showed measurable leakage in 2 of the 3 samples tested (see Table 2, Figure 2). There was no statistically significant difference found in the measurable leakage between the Neodent Drive CM and the Ankylos connection types; this should be interpreted with care since the sample size is small. A comparison was made between the Southern-External Hex tightened at old $(20 \mathrm{Ncm})$ and new $(45 \mathrm{Ncm})$ torque values. The mean measurable leakage for those IACs torqued to a value of $20 \mathrm{Ncm}$ was $1.899 \mathrm{EU}$ and those torqued to $45 \mathrm{Ncm}$ was $0.355 \mathrm{EU}$; however, we could not draw any statistically significant differences between the two due to the limited sample size. Further research is required into the effects of torqueing the external hex to $45 \mathrm{Ncm}$ especially with regard to screw loosening and fatigue. The Southern-Internal Hex IAC showed the highest mean measurable leakage at 5.409 EU. Separation of the Internal Hex IAC occurred in 2 of the 3 samples (see Table 2, Figure 2) because of screw loosening; this contributed to the higher leakage values detected. It is suspected that the lack of intimacy between abutment and implant and a low screw torque value may have facilitated screw loosening. The small sample size in this study limited the statistical comparisons and caution should be taken when interpreting the comparisons between similar connections.

This in vitro study reflects the effectiveness of the implantabutment connection seal whilst agitated on a platform shaker; however, the implants were not subjected to forces and movements as expected in vivo. Hence, it should be noted that, in the oral cavity, implant connections may exhibit different behavior. It is expected that the leakage reported in this study is less than one would witness when functional in the mouth due to masticatory forces.

This study only reports on four of the most widely used implant systems in South Africa out of a total of approximately 220 systems worldwide [14]. Many other implants systems available are untested and leakage values should not be extrapolated to similar IAC designs.

The use of a sample size of three per connection presents a limitation to the power of the study. However, due to the 
high costs of the study, a minimum number of implants was used that would allow for statistical comparison.

According to Hou et al. in 2013 [10], it was documented that microbial endotoxin alone proved to be a sufficient stimulus to upregulate the osteoclastic activity in bone metabolism. This interaction initiates a net bone loss in the affected region. Microbial endotoxin leakage from an implant connection may induce the same effect on peri-implant bone leading to peri-implantitis and eventual bone loss. Although implant success and/or survival is not determined solely by the connection and associated microbial leakage, it may be one variable the clinician could control when striving for more predictable results. The biologic nature of amoebocyte lysate testing and the small sample sizes suggests that results should be interpreted with caution; however, our data shows that not all IACs leak equally.

\section{Conclusion}

In conclusion, morse-like connection types performed better than other design types. This suggests that a morse-like design may contribute more significantly than the case whether the design is based on an overall internal or external configuration. The minimum amount of acceptable leakage (if at all) is still undefined. Until this principle is better understood, implant connection selection still remains a clinician's preference rather than a patient's biologic requirement.

\section{Competing Interests}

The authors declare that there is no conflict of interests regarding the publication of this paper.

\section{Acknowledgments}

Thanks are due to Straumann, Neodent, Dentsply, and Southern Implants for their considerable sponsorships and without whose cooperation this research would not have been possible. Special thanks are due to Professor Ugo Ripamonti, Director of Bone Research Unit, University of the Witwatersrand, for the unwaivering guidance and for providing suitable premesis for conducting this work. Thanks are due to Petra Gaylard for her statistical expertise and Jen Lab for their support throughout the study.

\section{References}

[1] P. I. Brånemark, B. O. Hansson, R. Adell et al., "Osseointegrated implants in the treatment of the edentulous jaw. Experience from a 10-year period," Scandinavian Journal of Plastic and Reconstructive Surgery. Supplementum, vol. 16, pp. 1-132, 1977.

[2] N. Muley, D. Prithviraj, and V. Gupta, "Evolution of external and internal implant to abutment connection," International Journal of Oral Implantology \& Clinical Research, vol. 3, no. 3, pp. 122129, 2012.

[3] G. Niznick, "The implant abutment connection: the key to prosthetic success," Compendium, vol. 12, no. 12, pp. 932-938, 1991.
[4] G. Orsini, S. Fanali, A. Scarano, G. Petrone, S. di Silvestro, and A. Piattelli, "Tissue reactions, fluids, and bacterial infiltration in implants retrieved at autopsy: a case report," The International Journal of Oral \& Maxillofacial Implants, vol. 15, no. 2, pp. 283286, 2000.

[5] P. Proff, I. Steinmetz, T. Bayerlein, S. Dietze, J. Fanghänel, and T. Gedrange, "Bacterial colonisation of interior implant threads with and without sealing," Folia Morphologica, vol. 65, no. 1, pp. 75-77, 2006.

[6] R. Adell, U. Lekholm, B. Rockler, and P. I. Branemark, "A 15year study of osseointegrated implants in the treatment of the edentulous jaw," International Journal of Oral Surgery, vol. 10, no. 6, pp. 387-416, 1981.

[7] V. K. Jansen, G. Conrads, and E.-J. Richter, "Microbial leakage and marginal fit of the implant-abutment interface," International Journal of Oral and Maxillofacial Implants, vol. 12, no. 4, pp. 527-540, 1997.

[8] M. Tesmer, S. Wallet, T. Koutouzis, and T. Lundgren, "Bacterial colonization of the dental implant fixture-abutment interface: an in vitro study," Journal of Periodontology, vol. 80, no. 12, pp. 1991-1997, 2009.

[9] S. Harder, B. Dimaczek, Y. Açil, H. Terheyden, S. FreitagWolf, and M. Kern, "Molecular leakage at implant-abutment connection-in vitro investigation of tightness of internal conical implant-abutment connections against endotoxin penetration," Clinical Oral Investigations, vol. 14, no. 4, pp. 427-432, 2010.

[10] G.-Q. Hou, C. Guo, G.-H. Song et al., "Lipopolysaccharide (LPS) promotes osteoclast differentiation and activation by enhancing the MAPK pathway and COX-2 expression in RAW264.7 cells," International Journal of Molecular Medicine, vol. 32, no. 2, pp. 503-510, 2013.

[11] F. B. Bang, "A bacterial disease of Limulus polyphemus," Bulletin of the Johns Hopkins Hospital, vol. 98, no. 5, pp. 325-351, 1956.

[12] A. Artiges, "Pharmacopeial standards: European pharmacopeia," in Agnès Artiges Encyclopedia of Pharmaceutical Technology, 3rd edition, 2013.

[13] SAS Institute, SAS Version 9.3 for Windows, SAS Institute, 2011.

[14] A. Jokstad, U. Braegger, J. B. Brunski, A. B. Carr, I. Naert, and A. Wennerberg, "Quality of dental implants," International Dental Journal, vol. 53, no. 6, pp. 409-443, 2003. 

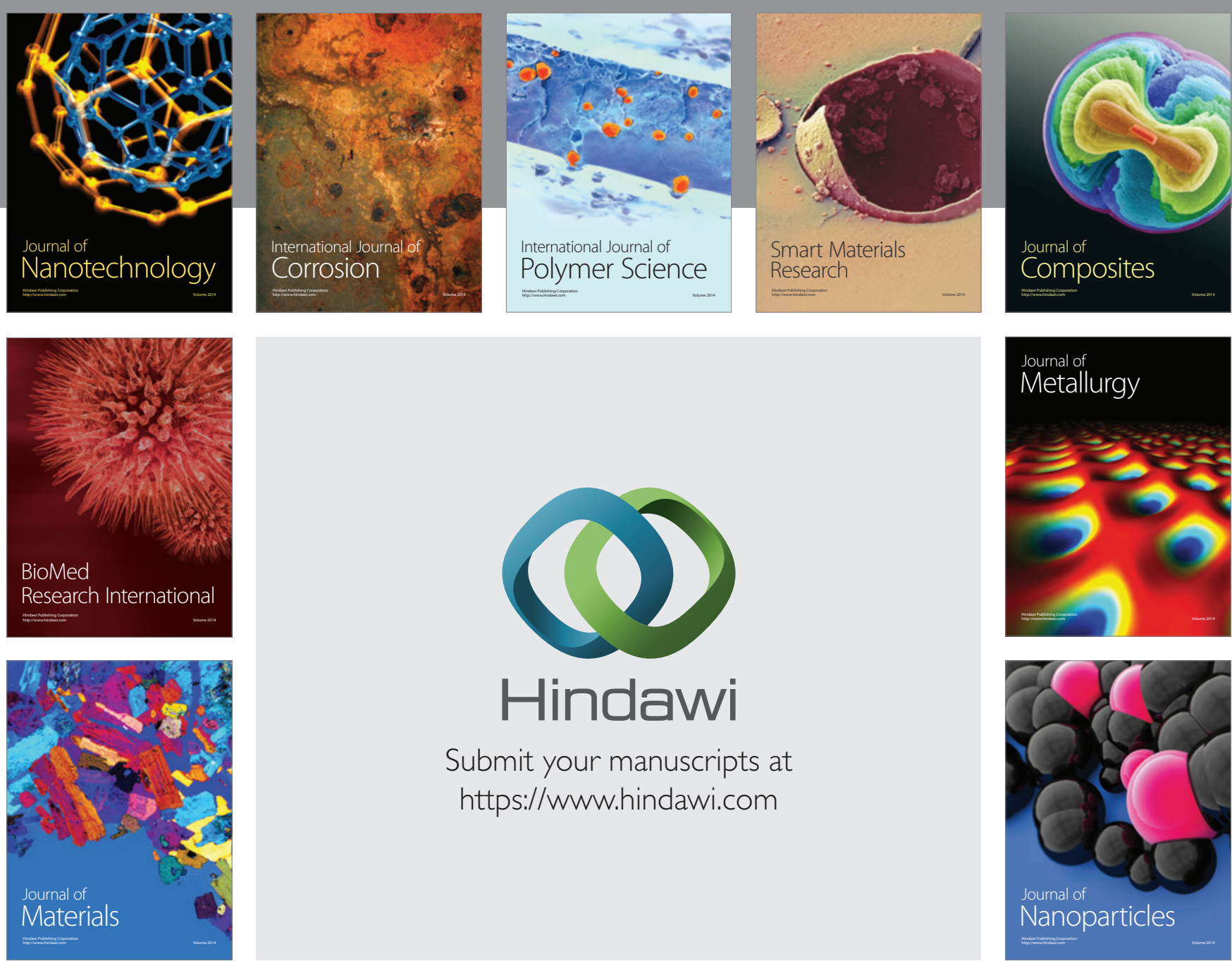

\section{Hindawi}

Submit your manuscripts at

https://www.hindawi.com

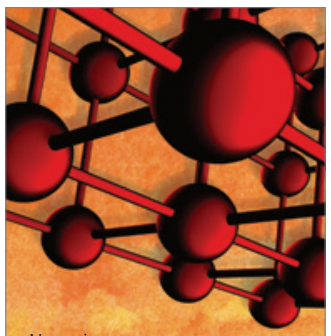

Materials Science and Engineering
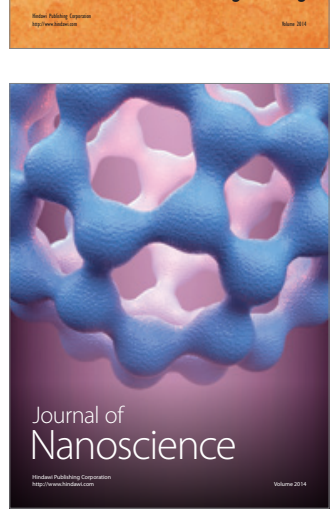
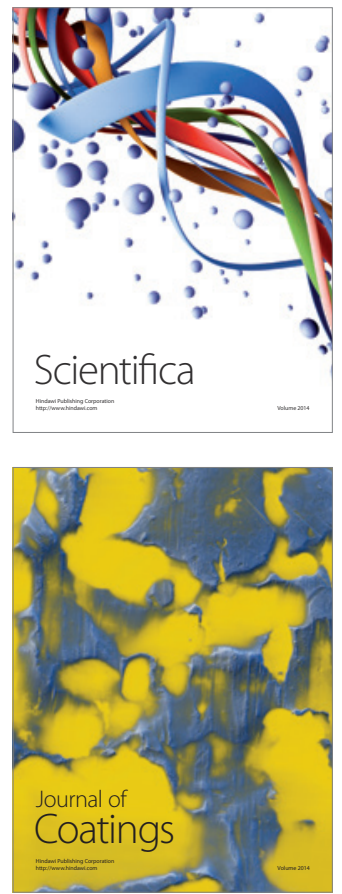
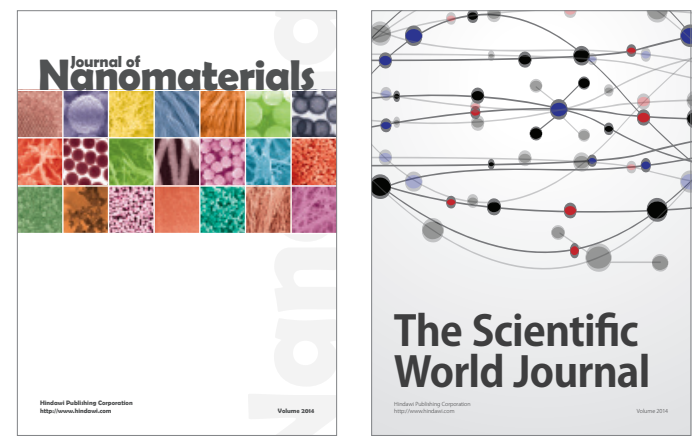

The Scientific World Journal
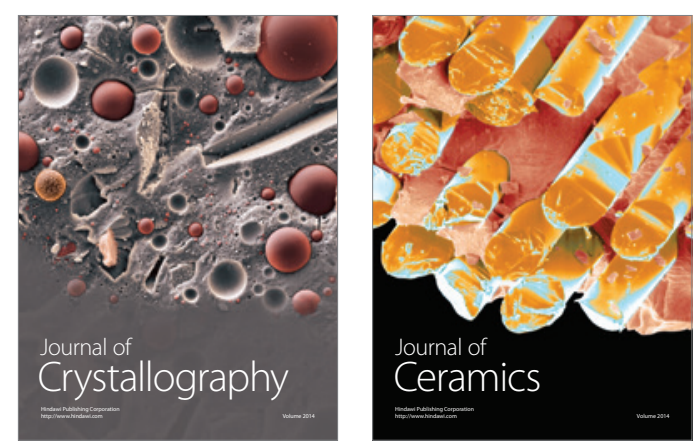
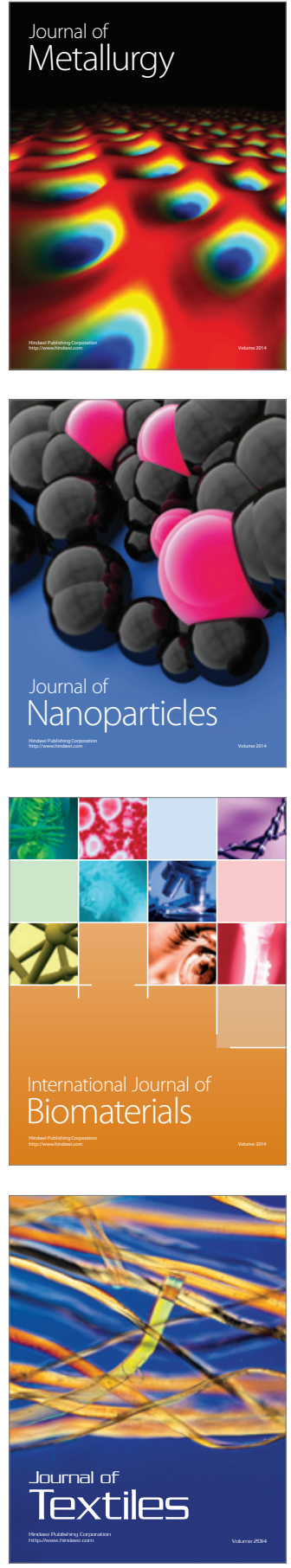